\title{
Information System Prototyping of Strawberry Maturity Stages using Arduino Uno and TCS3200
}

\author{
Ariagi Juliano $^{1}$, Ade Hendri Hendrawan ${ }^{2}$, Ritzkal $^{3}$ \\ 1, 2, ${ }^{3}$ Laboratorium Net Centric Computing, Program Studi Teknik Informatika, Universitas Ibn Khaldun Bogor, \\ Indonesia \\ 19ariagijuliano@gmail.com, ${ }^{2}$ hendri@uika-bogor.ac.id, ${ }^{3}$ ritzkal@uika-bogor.ac.id
}

\begin{abstract}
Strawberry is one of the commodities of subtropical fruits growing in Indonesia. It has a high economic value, attractive appeal in a red and fresh sweet fruit. The color of a strawberry shows its maturity stages, and the strawberry maturity stages affect postharvest quality. The research aimed to design and implement a tool to approve and apply the maturity stages of strawberries using Arduino Uno and display the information on the web. The method included needs analysis and analysis of work, and the design consisted of hardware design and network design. The testing consisted of TCS3200 sensor testing, LCD testing, servo motor testing, and WEB testing. The results of this study found that when the strawberry fruit was declared mature by the TCS3200 sensor as the color detection sensor, the LCD would display the texts, and the servo would open. The system on the WEB would display the total information of the sorted strawberries.
\end{abstract}

Keywords - Strawberry, TCS3200, WEB.

\section{INTRODUCTION}

Strawberry is one of the fruit subtropical commodities that have the potential to be developed in Indonesia. It has a great market opportunity for Indonesian strawberry farmers. The maturity stages of the fruit are affected by its color, namely bright red, red, pseudo red, or pseudo white. Specifically, fruit color is a factor intimately associated with fruit maturity, which is sometimes visually difficult to distinguish between immature, mature, or overripe. It is sometimes challenging for the farmers during the harvest time to distinguish the maturity stages of the strawberries visually.

The strawberry farmers traditionally indicated the ripening stages by parameters such as size, weight, and color, according to defined visual 'grading' schemes. Hence, a tool to indicate the stages of strawberry maturity based on Arduino Uno and RGB color web is designed.Some published researchers have conducted research using color sensors. Zia et al. developed a microfluidic portable laboratory-on-disc treatment center software by color sensors used for blood plasma use [1]. Kabachok and Zhigulin designed, developed, and built a digital CCD spectrometer playback using CCD color sensors [2]. IMAGE processes the control system and transfers intelligent traffic using Arduino was approved by Sathuluri et al. The system used color sensors using camera sensors to implement objects [3]. Detection of three visual impairments, namely Strabismus, blind spots, and blurred vision in rural areas using Raspberry PI using Hirschberg test, visual fields, and visual acuity was supported by Paglinawan et al. to activate three visual disturbances using a camera sensor that detects color, size, and shape [4]. The development of walking for the visually impaired started by Kamal et al. The system used a camera that uses a microcontroller [5].

A technique of borrowing colors using the Pixy CMUcam5 sensor, Arduino MEGA microcontroller, ultrasonic sensor, servo motor, motor driver, and transaxle motor for wheelchair followers was shared by Ahmad et al. [6]. Ibrahim et al. examined an RGB-D visual feedback controller for steering systems compatible with a system consisted of a camera sensor using a Kinect sensor to change color [7]. IoT-based smart irrigation systems and nutrient detection with disease analysis, that used a color sensor and a camera to identify the disease, were supported by Rau et al. [8]. Blood auditory systems in hemodialysis therapy, using optical sensors to convert blood, was reviewed by Sathiya Devi [9]. Ahmad et al. investigated the Bionic Kinect device, which helped blind people through haptic and voice feedback using the Kinect sensor [10].

Research on the camera as the color sensor to detect the color of an object has been conducted. An automatic potato ranking with fuzzy logic was investigated by Bhagat and Markande. The system used a camera as the sensor to detect the color, shape, and size of potatoes [11]. Detection of Strong and Embedded Visual Barriers on Autonomous Lawn Mowers was investigated by Franzius et al. using a camera as a sensor to detect the color of grass [12]. Controlling children's toy tanks using image processing techniques was investigated by Tse et al. The color sensor used a camera used to detect objects [13]. Smart Hole Detection and Reporting through Image Processing using a Raspberry-Pi Microcontroller investigated by Garcillanosa et al. using a camera as a sensor to detect a hole required a color sensor [14]. A real-time color-based robot arm sorting system was investigated by Jia, Yang, and Saniie using a camera sensor to do the sorting and detect the color of an object [15].

Research on LDR and LED as sensors to detect objects have been conducted. Murthy et al. conducted an experimental study on linear displacement measurement 
sensors using the RGB color variation technique with a PID controller. The system consisted of two LDRs and LEDs placed on one side and reflective paper with color-coded RGB on the opposite side [16]. Wali-ur-Rahman et al. investigated robot arms with proximity and color detection using a camera as a sensor to detect color [17]. Sonal, Raninga, and Patel designed and implemented the RGB color line robot. The color sensor system was built using colored LEDs and LDR as the main components [18]. Khade, Naik, and Patil designed all color line follower sensors with automatic calibration capabilities using LDR and LED sensors to detect the color of the line [19]. Panie and Mutiara developed a robot arm for color-based goods sorter in a factory using a TCS3200 sensor with web-based monitoring system. The system used TCS3200 sensors [20].

Based on the background and literature review, the author aims to study and make a model design to sort of strawberries by using an Arduino Uno microcontroller as a controller module and TCS3200 sensor as an input that detects the maturity of strawberries to detect the color of RGB (red green blue). A Web is useful for displaying information on the number of ripe and raw strawberries that have been sorted based on the tool designed. The designed web is connected to the Net-Centric Computing Laboratory research server. The information and data sent either wired or wireless so that computer network users can exchange the documents and data. An ethernet shield used as a connection between Arduino and the internet and the web as a monitor interface.

\section{METHODS}

The study compiled research objectives related to direction and objectives. Figure 1 show the methodology is centered on the Information System Prototyping of Strawberry Maturity Stages using Arduino Uno [21]-[24] and TCS3200 [25][26]. The development processes integrated in the approach were hardware-software design, software implementation, hardware implementation, and testing of the sensor, LCD, motor servo, and web.

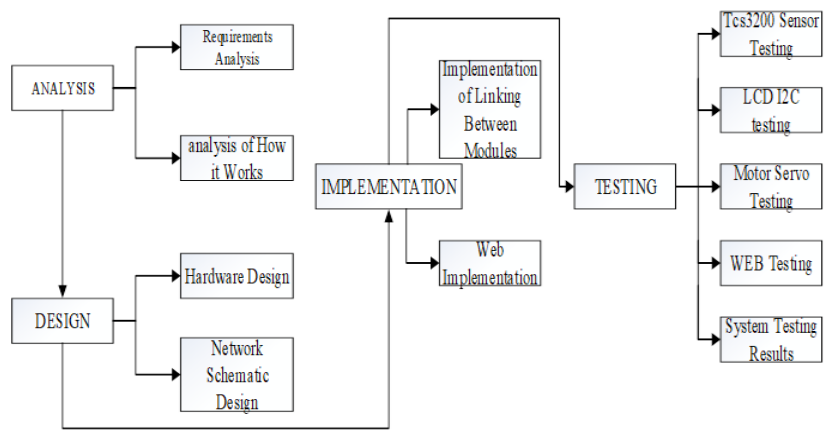

Fig. 1. Research Flow

\section{A. Hardware Requirements}

In the need analysis phase, there was hardware design to support the research consisting of an Arduino Uno [27][30], a servo, a motor DC, a TCS3200 sensor, a USB, a jumper, cables, a Laptop, an Ethernet shield, an LCD, and an adaptor. Figure 2 illustrates the hardware design.

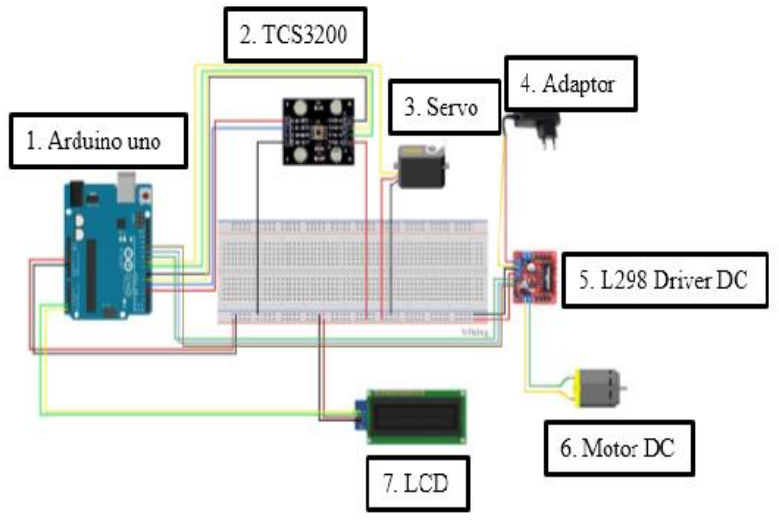

Fig. 2. Hardware Design

\section{B. How the System Work}

Figure 3 explains how the system works, starting from detecting ripe and raw strawberries. The TCS3200 sensor detected colors based on the RGB color of the strawberries and sent commands to the Arduino Uno and Ethernet Shield. The source code was stored in a server with program instructions. The program instructions communicated with the WEB using the source code, and sent the information of the sorted strawberries into the WEB.

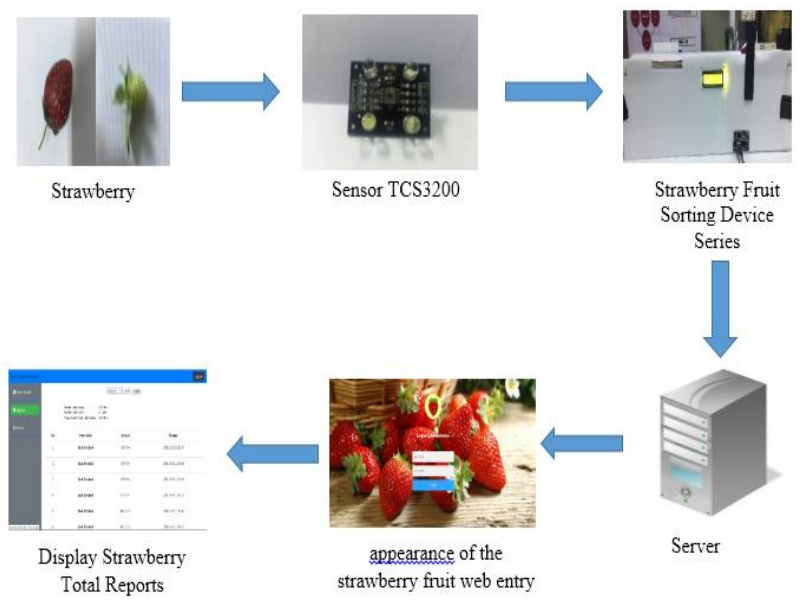

Fig. 3. How the system work

\section{Design}

\section{Overall Block Diagram}

The diagram of the block system seen in Figure 4 shows that the TC3200 sensor is an input, and the Arduino Uno is a process and directly forwarded.

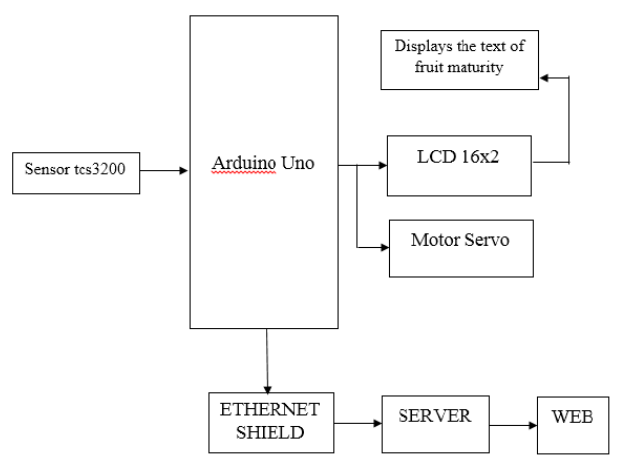

Fig. 4. Overall Block Diagram 


\section{Hardware Schematic Sequence}

There were several stages of the hardware schematic sequence. At the first stage, the TCS3200 sensor schematic circuit was connected to the Arduino Uno on pins 4, 5, 6, 7, and 8 . The two LCD schematic circuits were connected to the Arduino Uno-SDA (Serial Data) pins to A4 and SCL (Serial Clock) to A5, the three-schematic series of servo motors to Arduino Uno on pin 9, and the four-L298 schematic circuits of DC motor drivers to the Arduino Uno-IN1 to pin 10 and IN2 to pin 11. The adapter was connected to the L298 DC motor driver.

\section{System Network Design}

Figure 5 illustrates the network design on a series of strawberry fruit sorting tool by displaying information on the strawberry fruit sorting web. The tool is connected to the SF90-24 switch with the IP address 192.168.3.116, using a UTP cable on port 17. After being connected to the SF9024 unmanageable switch and the UTP cable, the fruit server is connected to the SWITCH port 4 to send data, in the form of the total sort of ripe strawberries and raw fruit, to the fruit server with the IP address 192.168.3.10. The users can access the web browser Http: /localhost/stroberi/index.php. to obtain the results of the strawberry sorter.

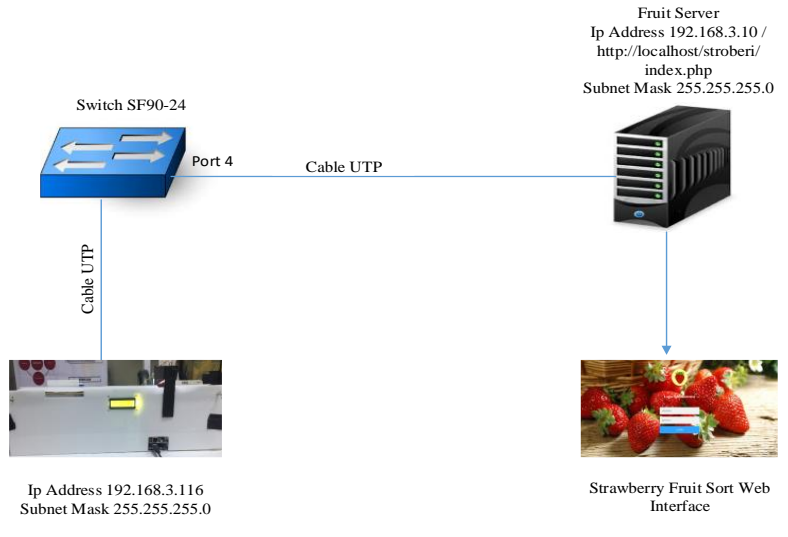

Fig. 5. System Network Design [31] [32]

\section{IMPLEMENTATION}

The stages of implementation include system flow, hardware implementation, and software implementation.

\section{A. System Flow}

The implementation stage was the assembly or installation of all components in the system. It aimed to ensure whether the system designed was running well or not. The research is described using the system flow as displayed in Figure 6.

\section{B. Software Implementation}

For the two devices to communicate in $\mathrm{C}$ language, which was the Arduino programming language, a library was required. The library was a library of TCS3200 used in this research, by connecting between the Arduino Uno and TCS3200 using jumper cables. The Arduino program source code is:

color();

Serial.print("R Intensity:");
Serial.print(red, DEC);

Serial.print(" G Intensity: ");

Serial.print(green, DEC);

Serial.print(" B Intensity : ");

Serial.print(blue, DEC);

Serial.println();

if $($ red $<$ blue $\& \&$ red $<$ green $)$

\{

Serial.println(" - (Red Color)");

\}

else if (blue < red \&\& blue < green)

\{

Serial.println(" - (Blue Color)");

delay(500);

\}

else if (green < red \&\& green < blue)

\{

Serial.println(" - (Green Color)");

delay $(500)$;

\}

\}

void color()

\{

digitalWrite(s2, LOW);

digitalWrite(s3, LOW);

//count OUT, pRed, RED

red $=\operatorname{pulseIn}($ out, digitalRead $($ out $)==$ HIGH ? LOW :

HIGH);

digitalWrite(s3, HIGH);

//count OUT, pBLUE, BLUE

blue $=$ pulseIn $($ out, digitalRead $($ out $)==$ HIGH ? LOW :

HIGH);

digitalWrite(s2, HIGH);

//count OUT, pGreen, GREEN

green $=$ pulseIn $($ out, digitalRead $($ out $)==$ HIGH $?$ LOW : HIGH);

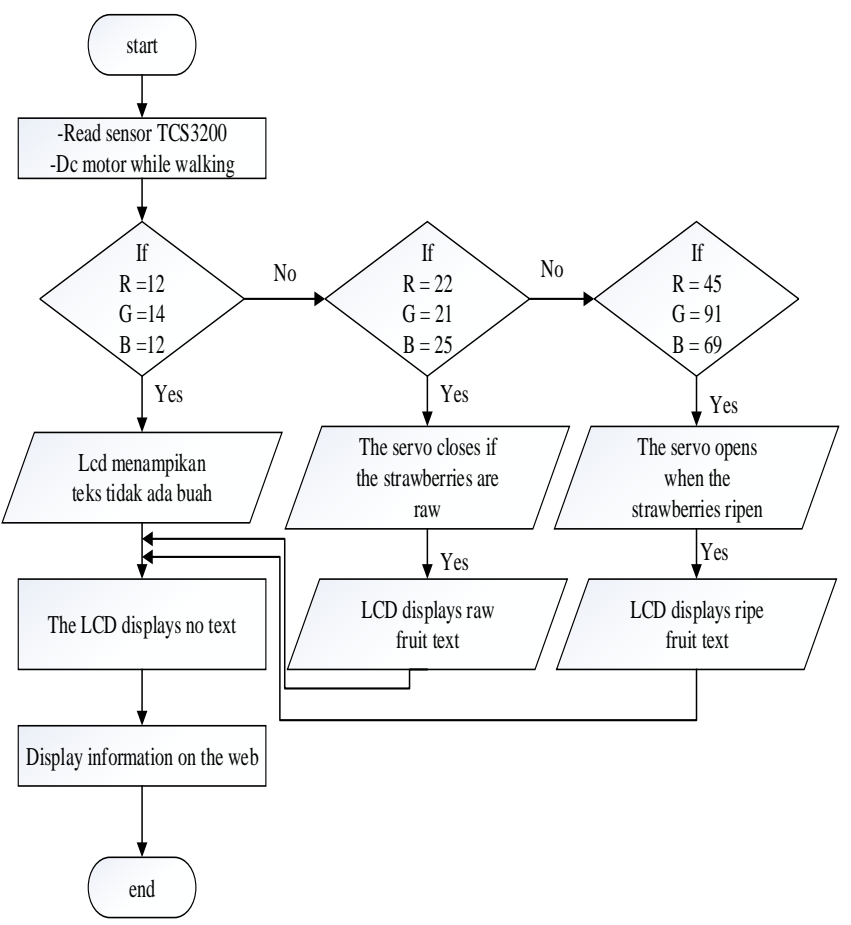

Fig. 6. Overall Block Diagram 


\section{B. Testing}

\section{Sensor Testing}

In the system, the TCS3200 sensor was the only sensor input for reading the color of RGB (red, green, and blue) as displayed in Figure 7. In the testing, the TCS3200 sensor was placed on the holder. The maturity of the strawberries was based on the RGB color

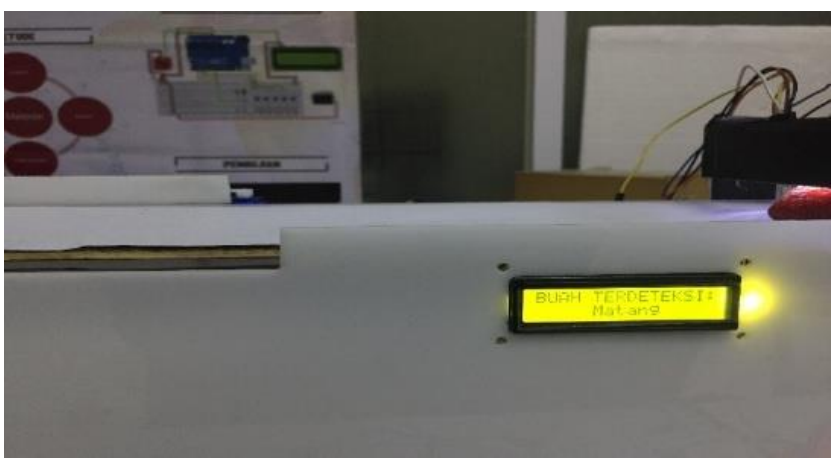

Fig. 7. TCS3200 Sensor Testing

\section{LCD Testing}

The LCD Testing aims to determine the ripe and immature strawberry fruit. Figure 8 shows that the strawberry is raw/unripe.

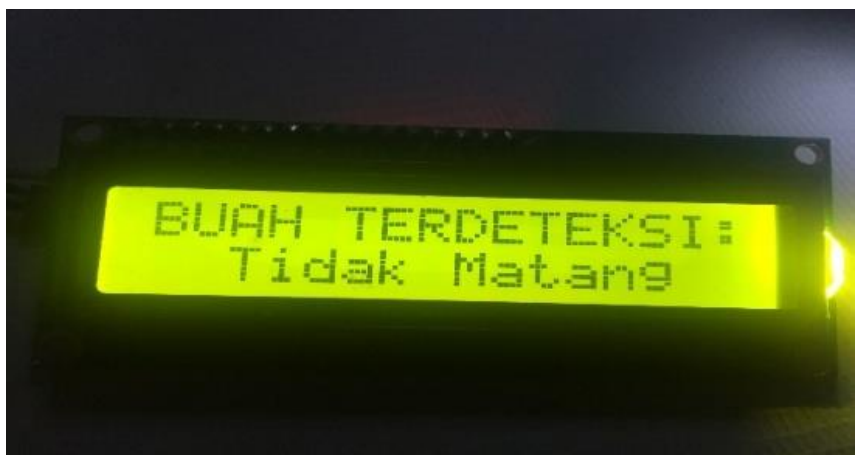

Fig. 8. LCD testing

\section{Servo Motor Testing}

Figure 9 shows that servo motor testing was performed by activating the servo movement using the configuration that had been made. The servo served to sort the raw and ripe strawberries. The servo would close when the strawberries were raw and vice versa. Figure 9 shows that in the "closed Servo" condition, there is an immature strawberry.

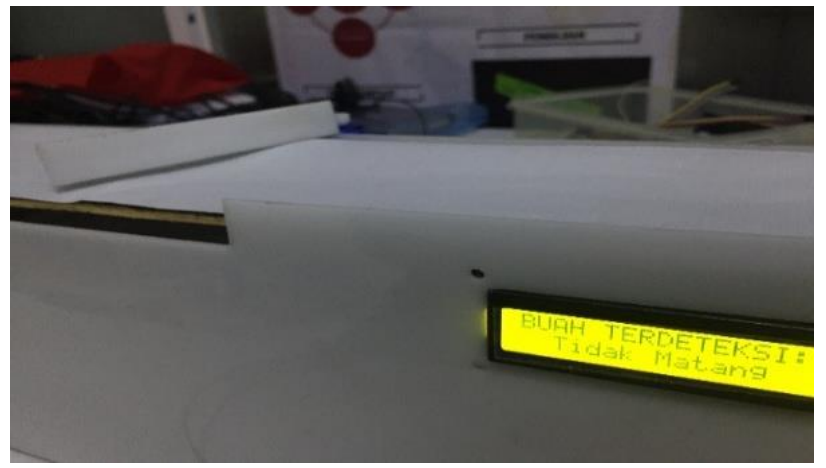

Fig. 9. Servo Motor Testing

\section{Web Testing}

The WEB testing was carried out to check the web as an output that serves to display the total information of sorted strawberries. Figure 10 shows the strawberry fruit web login interface as the output of the system.

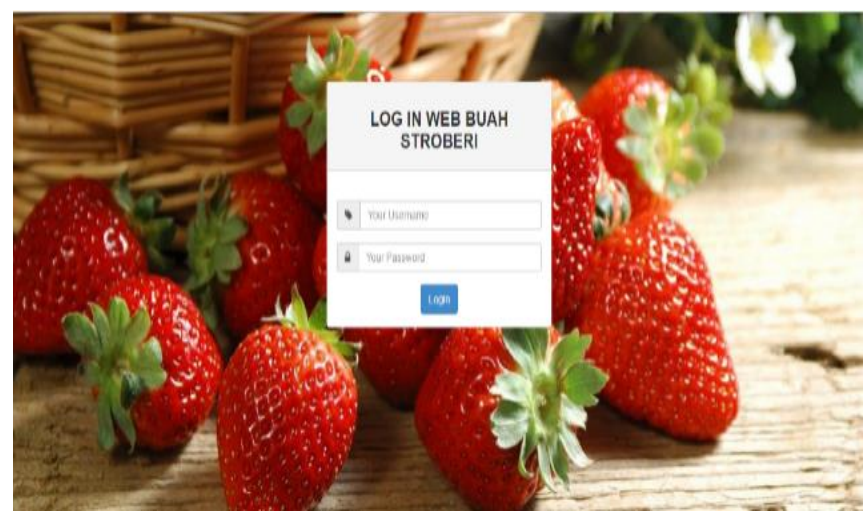

Fig. 10. Strawberry web login interface

Figure 11 shows the display information of ripe and raw strawberries that have been sorted and displayed the total and total number of fruits that have been sorted along with the date and time.

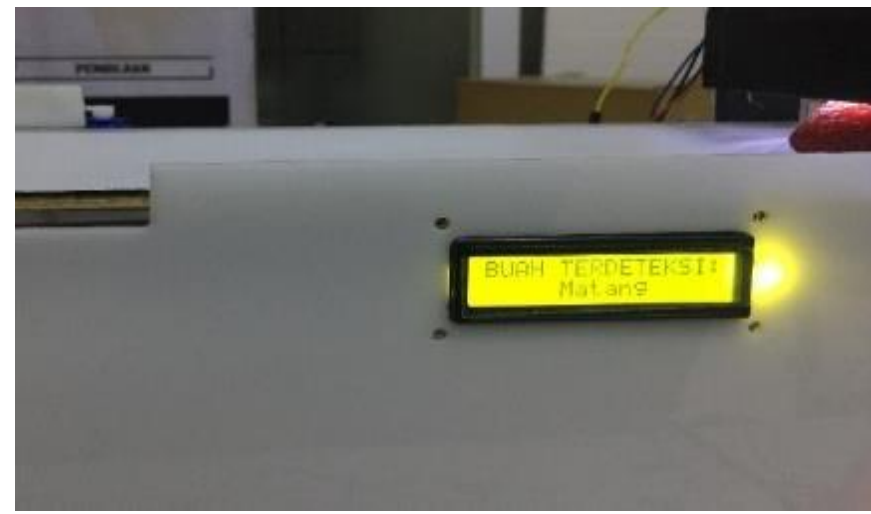

Fig. 11. The Strawberry Fruit Web Report

The RGB Color Composition of Immature Fruits is shown in Table I. From the table it appears that there are four holes containing strawberry data, RGB values, servo and description. It appears that the color composition of the immature RGB fruit has a small RGB value.

TABLE I. RGB COLOR COMPOSITION OF FRUITS NOT MATURE

\begin{tabular}{|c|c|c|c|c|}
\hline NO & Strawberry & $\begin{array}{l}\text { RGB color } \\
\text { compositio } \\
n\end{array}$ & Servo & Description \\
\hline 1. & & $\begin{array}{l}\mathrm{R}: 22 \\
\mathrm{G}: 21 \\
\mathrm{~B}: 25\end{array}$ & $\mathrm{ON}$ & $\begin{array}{l}\text { The sensor } \\
\text { detects } \\
\text { immature } \\
\text { fruit. The } \\
\text { RGB servo } \\
\text { sensor } \\
\text { closes }\end{array}$ \\
\hline 2. & & $\begin{array}{l}\mathrm{R}: 20 \\
\mathrm{G}: 19 \\
\mathrm{~B}: 28\end{array}$ & $\mathrm{ON}$ & $\begin{array}{l}\text { The sensor } \\
\text { detects } \\
\text { immature } \\
\text { fruit. RGB } \\
\text { servo sensor } \\
\text { closes }\end{array}$ \\
\hline
\end{tabular}


The composition of the color of the strawberries is presented in Table 2. From this table, there are four holes that contain strawberry data, RGB values, servo and description. Strawberry fruit has a large RGB value. This fruit shows that the strawberry fruit is ripe.

TABLE II. COLOR COMPOSITION OF RIPE STRAWBERRY FRUITS

\begin{tabular}{|c|c|c|c|c|}
\hline No & Strawberry & $\begin{array}{l}\text { Rgb Color } \\
\text { Composition }\end{array}$ & Servo & Information \\
\hline 1. & & $\begin{array}{l}\mathrm{R}: 45 \\
\mathrm{G}: 91 \\
\mathrm{~B}: 69\end{array}$ & OFF & $\begin{array}{l}\text { The sensor } \\
\text { detects ripe } \\
\text { fruit. RGB } \\
\text { servo sensor } \\
\text { opens. }\end{array}$ \\
\hline 2. & . & $\begin{array}{l}\text { R : } 38 \\
\text { G : } 75 \\
B: 58\end{array}$ & OFF & $\begin{array}{l}\text { The sensor } \\
\text { detects ripe } \\
\text { fruit. RGB } \\
\text { servo sensor } \\
\text { opens }\end{array}$ \\
\hline 3. & & $\begin{array}{l}\mathrm{R}: 35 \\
\mathrm{G}: 59 \\
\mathrm{~B}: 48\end{array}$ & OFF & $\begin{array}{l}\text { The sensor } \\
\text { detects ripe } \\
\text { fruit. RGB } \\
\text { servo sensor } \\
\text { closes }\end{array}$ \\
\hline 4. & & $\begin{array}{l}\mathrm{R}: 38 \\
\mathrm{G}: 86 \\
\mathrm{~B}: 71\end{array}$ & OFF & $\begin{array}{l}\text { The sensor } \\
\text { detects ripe } \\
\text { fruit. RGB } \\
\text { servo sensor } \\
\text { opens }\end{array}$ \\
\hline
\end{tabular}

\section{CONCLUSION}

The design of the prototype Physical Information System of Strawberry Maturity Sorting Information System Based on RGB Color Assisted by Arduino Uno Web Based with TCS3200 sensor can display information on ripe strawberries, and the LCD can display the maturity of strawberry fruit. The results of total strawberry fruit sorting on the WEB-Assisted Strawberry Maturity Sorting System series has worked well.

\section{REFERENCES}

[1] A. B. Zia, M. A. Ali, M. O. Zeb, U. Shafiq, S. R. Fida, and N. Ahmed, "Development of microfluidic lab-on-disc based portable blood testing point-of-care diagnostic device," in 2016 IEEE EMBS Conference on Biomedical Engineering and Sciences (IECBES), 2016, pp. 142-145.

[2] S. Kabachok and D. Zhigulin, "Design of digital CCD spectrometer," in 2016 IEEE 7th International Conference on Advanced Optoelectronics and Lasers (CAOL), 2016, pp. 48-50.

[3] M. R. Sathuluri, S. K. Bathula, P. Yadavalli, and R. Kandula, "IMAGE processing based intelligent traffic controlling and monitoring system using Arduino," in 2016 International Conference on Control, Instrumentation, Communication and Computational Technologies (ICCICCT), 2016, pp. 393-396.

[4] A. C. Paglinawan et al., "Detection of three visual impairments: Strabismus, blind spots, and blurry vision in rural areas using Raspberry PI by implementing hirschberg, visual field, and visual acuity tests," in 2017IEEE 9th International Conference on Humanoid, Nanotechnology, Information Technology, Communication and Control, Environment and Management (HNICEM), 2017, vol. 2018-Janua, pp. 1-9.

[5] M. M. Kamal, A. I. Bayazid, M. S. Sadi, M. M. Islam, and N. Hasan, "Towards developing walking assistants for the visually impaired people," in 2017 IEEE Region 10 Humanitarian Technology Conference (R10-HTC), 2017, vol. 2018-Janua, pp. 238-241.

[6] M. F. Ahmad, H. J. Rong, S. S. N. Alhady, W. Rahiman, and W. A. F. W. Othman, "Colour tracking technique by using pixy
CMUcam5 for wheelchair luggage follower," in 2017 7th IEEE International Conference on Control System, Computing and Engineering (ICCSCE), 2017, vol. 2017-Novem, no. November, pp. 186-191.

[7] M. F. Ibrahim, F. Zulkifli, M. R. H. M. Nizam, A. B. Huddin, and A. Hussain, "An RGB-D visual feedback controller for a differential drive attachable wheel system 1," in 2017 6th International Conference on Electrical Engineering and Informatics (ICEEI), 2017, vol. 2017-Novem, pp. 1-7.

[8] A. J. Rau, J. Sankar, A. R. Mohan, D. Das Krishna, and J. Mathew, "IoT based smart irrigation system and nutrient detection with disease analysis," in 2017 IEEE Region 10 Symposium (TENSYMP), 2017, pp. 1-4.

[9] G. S. Sathiya devi, "Blood leakage monitoring system in Hemodialysis therapy," in 2016 International Conference on Communication and Electronics Systems (ICCES), 4992, pp. 1-5.

[10] F. Ahmad, Tanveerulhaq, I. Ishaq, D. Ali, and M. F. Riaz, "Bionic Kinect device to assist visually impaired people by haptic and voice feedback," in 2016 International Conference on Bio-engineering for Smart Technologies (BioSMART), 2016, pp. 1-4.

[11] N. B. Bhagat and S. D. Markande, "Automatic grading of potatoes with fuzzy logic," in 2016 Online International Conference on Green Engineering and Technologies (IC-GET), 2016, pp. 1-4.

[12] M. Franzius, M. Dunn, N. Einecke, and R. Dirnberger, "Embedded Robust Visual Obstacle Detection on Autonomous Lawn Mowers," in 2017 IEEE Conference on Computer Vision and Pattern Recognition Workshops (CVPRW), 2017, vol. 2017-July, pp. 361369.

[13] A. Tse, J. Saegnwipharat, K. Supayanant, and C. Pornpanomchai, "Controlling children-toy tank by using image processing technique," in 2016 Fifth ICT International Student Project Conference (ICT-ISPC), 2016, pp. 73-76.

[14] M. M. Garcillanosa, J. M. L. Pacheco, R. E. Reyes, and J. J. P. San Juan, "Smart Detection and Reporting of Potholes via ImageProcessing using Raspberry-Pi Microcontroller," in 2018 10th International Conference on Knowledge and Smart Technology (KST), 2018, pp. 191-195.

[15] Y. Jia, G. Yang, and J. Saniie, "Real-time color-based sorting robotic arm system," in 2017 IEEE International Conference on Electro Information Technology (EIT), 2017, pp. 354-358.

[16] A. Murthy, S. S. Rao, M. A. Herbert, and Navin Karanth P, "Experimental study on linear displacement measurement sensor using RGB color variation technique with PID controller," in 2017 International Conference on Computer, Communications and Electronics (Comptelix), 2017, pp. 241-247.

[17] M. Wali-ur-Rahman, S. I. Ahmed, R. Ibne Hossain, T. Ahmed, and J. Uddin, "Robotic Arm with Proximity and Color Detection," in 2018 IEEE 7th International Conference on Power and Energy (PECon), 2018, pp. 322-326.

[18] G. Sonal, P. Raninga, and H. Patel, "Design and implementation of RGB color line following robot," in 2017 International Conference on Computing Methodologies and Communication (ICCMC), 2017, vol. 2018-Janua, no. Iccmc, pp. 442-446.

[19] K. Khade, R. Naik, and A. Patil, "Design of all color line follower sensor with auto calibration ability," in 2017 7th International Symposium on Embedded Computing and System Design (ISED), 2017, vol. 2018-Janua, pp. 1-5.

[20] G. I. E. Panie and A. B. Mutiara, "Development of Robotic Arm for Color Based Goods Sorter in Factory Using TCS3200 Sensor with a Web-Based Monitoring System," in 2018 Third International Conference on Informatics and Computing (ICIC), 2018, pp. 1-6.

[21] F. C. Ferreira, M. F. Santos, and V. B. Schettino, "Computational vision applied to mobile robotics with position control and trajectory planning: Study and application," in 2018 19th International Carpathian Control Conference (ICCC), 2018, no. Section VII, pp. 253-258.

[22] S. Saha, R. Hasan Rajib, and S. Kabir, "IoT Based Automated Fish Farm Aquaculture Monitoring System," in 2018 International Conference on Innovations in Science, Engineering and Technology (ICISET), 2018, no. October, pp. 201-206. 
[23] J.-H. Li, Y.-S. Ho, and J.-J. Huang, "Line Tracking with Pixy Cameras on a Wheeled Robot Prototype," in 2018 IEEE International Conference on Consumer Electronics-Taiwan (ICCE-TW), 2018, pp. 1-2.

[24] A. I. Rusu, A. Florescu, and S. G. Rosu, "Efficient Navigation of a Robot Based on an Improved Contrast of Colours Algorithm," in 2018 IEEE 24th International Symposium for Design and Technology in Electronic Packaging (SIITME), 2018, no. 33, pp. $37-42$.

[25] A. Singh, N. B. Balam, A. Kumar, and A. Kumar, "An Intelligent Color Sensing system for building wall," in 2016 International Conference on Emerging Trends in Communication Technologies (ETCT), 2016, pp. 1-4.

[26] H. Rashid, A. S. . R. Al-Mamun, M. S. R. Robin, M. Ahasan, and S. M. T. Reza, "Bilingual wearable assistive technology for visually impaired persons," in 2016 International Conference on Medical Engineering, Health Informatics and Technology (MediTec), 2016, pp. 1-6.

[27] Revantino et al., "Reconstruction of Color Mixing Model Using Tunable Light-Emitting Diode with Unequal Radiated Power," in 2018 IEEE 3rd Optoelectronics Global Conference (OGC), 2018, pp. 56-59.
[28] R. Alimuin, E. Calilung, and E. Dadios, "Implementation of machine vision as an input to a fuzzy water level control system," in 2017IEEE 9th International Conference on Humanoid, Nanotechnology, Information Technology, Communication and Control, Environment and Management (HNICEM), 2017, vol. 2018-Janua, pp. 1-6.

[29] M. R. Usikalu, B. M. Allen, W. A. Ayara, and I. O. Babarimisa, "Design of Autocrash Emergency Locator," in 2018 IEEE Conference on Technologies for Sustainability (SusTech), 2018, pp. $1-4$.

[30] S. Mahat, S. H. Yusoff, S. A. Zaini, N. S. Midi, and S. Y. Mohamad, "Automatic Metal Waste Separator System In Malaysia," in 2018 7th International Conference on Computer and Communication Engineering (ICCCE), 2018, pp. 366-371.

[31] Ritzkal, "Manajemen Jaringan untuk Pemula," UIKA Press, 2018.

[32] S. Syaiful, D. Hariyadi, "Case Study on Sustainable T-Junction Cibinong City Mall (CCM) in Bogor Indonesia, Asian Research Publishing Network (ARPN) Journal of Engineering and Applied Science, vol. 14, no. 17, 2019. 